\title{
Dopaminergic dysfunction in neuropsychiatric disorders. Pathophysiology, current therapeutics, and future perspectives
}

\author{
Chandrasekhar Chanda, Sobhitha Surepalli \\ Department of Biotechnology, Koneru Lakshmaiah Education Foundation, Vaddeswaram, Guntur, Andhra Pradesh, India
}

Neuropsychiatria i Neuropsychologia 2019; 14, 1-2: 39-47

Address for correspondence:

Asst. Prof. Dr. Chandrasekhar Chanda

Department of Biotechnology

Koneru Lakshmaiah Education Foundation

Green Fields

Vaddeswaram, 522502

Guntur, Andhra Pradesh, India

e-mail: chandrasekharchanda02@kluniversity.in

\begin{abstract}
Dopaminergic signalling is crucial for a variety of brain functions, and abnormal dopamine regulation leads to neuropsychiatric disorders. Dopamine (DA) receptors are members of the G protein-coupled receptors (GPCRs) superfamily, with seven transmembrane spanning domains. DA, upon release from pre-synaptic neurons, activates dopamine receptor subtypes D1 to D5 and induces Gas/olf- and Gai/o-mediated intracellular signalling. Defects in DA signalling cause either over-activation or dysfunction of DA regulation, leading to major psychiatric and neurological disorders, including Parkinson's, schizophrenia, attention deficit with hyperactivity disorder, and bipolar disorder. Molecules that act as antagonists/agonists on D2/D3 receptors have been used clinically to treat many neuropsychiatric and neurodegenerative disorders. Most of the anti-psychotic drugs in use are primarily based on D2 receptor antagonism and serotonin receptor antagonism. However, antipsychotic drugs were developed 50 years ago, and the efficacy of these drugs has not been refined/upgraded very much. Thus, there is a great need to develop novel therapeutic strategies in designing/discovering a newer class of drugs. This can be achieved by having a better understanding about DA regulation and dopaminergic signalling in neuropsychiatric disorders. The in silico approach can be a tool for studying DA receptors and other protein targets involved in dopaminergic signalling. Utilising the existing knowledge on DA signalling in combination with various in silico approaches can be helpful in designing new chemical entities (NCEs). This review focuses on receptor functioning and dopaminergic signalling in major neuropsychological disorder, current therapeutic strategies, and future perspectives.
\end{abstract}

Key words: dopamine, dopamine receptor, dopaminergic signalling, neuropsychiatric disorders.

\section{Introduction}

\section{Dopamine and dopaminergic biosynthetic pathways}

Neuropsychiatric disorders have been known for thousands of years, the earliest known record of the disease dated back as early as 600 B.C. Physicians and scientists remained clueless for several decades in understanding neuropsychiatric disorders. However, as scientists have started to understand the structure and function of brain, different strategies of diagnosis and treatment have been made available from the beginning of $20^{\text {th }}$ century. At present, existing literature states that mental illness or neurological disorders mostly originate from biological modifications, which are highly influenced by the changed lifestyle of human beings. The so- called biological modifications are found at the level of neuronal crosstalk, which is mediated by chemical messengers called neurotransmitters. Dopamine (DA) is a key neurotransmitter, found to play a critical role in the midbrain region. DA neurons are categorised into two important groups: one is known to regulate neuroendocrine system, and the second group is found to play an important role in the regular functions of the brain such as motor behaviour, learning, and memory. Structurally, DA is an organic chemical belonging to the catecholamine family, which is synthesised by cells of medulla in the brain and adrenal glands in kidneys (Seeman 2010a). DA helps in communication between neurons. DA plays a crucial role in four major dopaminergic pathways present in the human brain: the mesolimbic, mesocortical, nigrostria- 


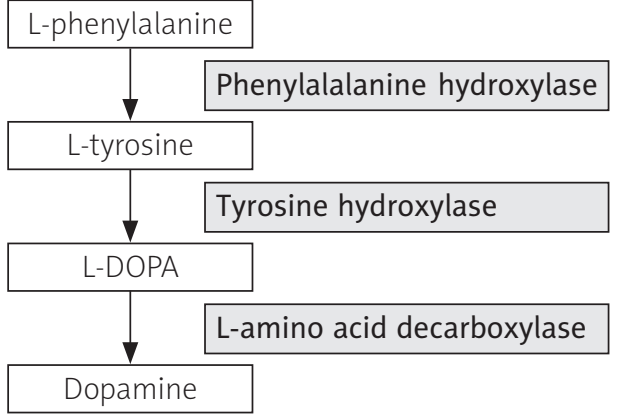

Fig. 1. Biosynthetic pathway of dopamine from precursor

\begin{tabular}{l|l|} 
Dopamine \\
Epinephrine
\end{tabular}

Fig. 2. Dopamine as a precursor for the synthesis of neurotransmitters

tal, and tuberoinfundibular pathways (Andén et al. 1964; Dahlström and Fuxe 1964). The reward pathway or mesolimbic pathway is responsible for driving human feelings for reward, motivation, and behaviour. Reward cognition is mainly due to increased levels of DA in the brain. Other dopaminergic pathways control motor functioning and hormonal release.

L-DOPA is the precursor of DA, which is synthesised by the biosynthetic pathways of L-phenylalanine or L-tyrosine (Musacchio 1975). The biosynthetic pathway of DA from $\mathrm{L}$-phenylalanine is shown in Figure 1. DA acts as precursor for the biosynthesis of the neurotransmitters norepinephrine and epinephrine. The biosynthetic pathway of epinephrine from $\mathrm{DA}$ is shown in Figure 2.

\section{Dopamine receptors}

DA transacts its neurological and psychological activities through well-defined membranelinked proteins called DA receptors. DA, upon release from presynaptic neurons, can either activate or inhibit DA receptors based on its localisation. Considering this ability of DA to modulate its receptors, DA receptors are rationally classified into two major classes, which belong to the $G$ protein family receptors (GPCRs). The criteria for the classification of DA receptor subtypes are based on its ability to modulate adenylyl cyclase activity. Based on structural and biochemical properties, DA receptor subtypes are divided into two classes: $\mathrm{D}_{1}$ and $\mathrm{D}_{2}$. Detailed information on different types of $\mathrm{DA}$ receptors is given in Table 1.

$\mathrm{D}_{1}$ class receptors or $\mathrm{D}_{1}$-like family receptors (which include $\mathrm{D}_{1}$ and $\mathrm{D}_{5}$ receptors) have the ability to activate adenylyl cyclase. $\mathrm{D}_{1}$ subtype is expressed in high levels in the nigrostriatal, mesolimbic, and mesocortical regions of the brain (Tiberi et al. 1991), whereas $\mathrm{D}_{5}$ subtype is expressed in low levels in the prefrontal cortex (PFC), premotor cortex, and substantia nigra of the brain (Rankin et al. 2006). The $\mathrm{D}_{2}$ class of receptors $\left(\mathrm{D}_{2}, \mathrm{D}_{3}, \mathrm{D}_{4}\right)$ inhibits the formation of cAMP by inhibiting adenylyl cyclase activity (Niznik and Van Tol 1992). D 2 DA receptors have higher expression levels in substantia nigra, ventral tegmental area, hypothalamus, amygdala, and hippocampus (Andén et al. 1964; Dahlström and Fuxe 1964). D receptors are expressed more in limbic areas, and $\mathrm{D}_{4}$ receptors are observed in the frontal cortex, amygdala, and hippocampus (Rondou et al. 2010).

\section{Dopamine receptor mediated signalling}

DA receptors are members of the GPCR superfamily, with seven transmembrane spanning domains. They activate heterotrimeric $G$

Table 1. Dopamine receptor classification

\begin{tabular}{|c|c|c|c|c|c|c|}
\hline \multirow{2}{*}{ Receptor } & & \multicolumn{2}{|c|}{ Function } & \multicolumn{2}{|c|}{ Distribution } & \multirow{2}{*}{$\begin{array}{l}\text { Amino } \\
\text { acids }\end{array}$} \\
\hline & & $\begin{array}{l}\text { Adenylate } \\
\text { cyclase }\end{array}$ & $\begin{array}{l}\text { PIP } \\
\text { turnover }\end{array}$ & Brain & Periphery & \\
\hline \multirow[t]{2}{*}{ D1-like } & D1 & Increases & Increases & Striatum nucleus accumbens & Heart, kidney & 446 \\
\hline & D5 & Increases & Increases & Hypothalamus, hippocampus & Vascular Kidney & 477 \\
\hline \multirow[t]{3}{*}{ D2-like } & D2 & Decreases & Decreases & Striatum substantia nigra & $\begin{array}{l}\text { Vascular heart } \\
\text { sympathetic ganglia }\end{array}$ & 414 \\
\hline & D3 & Decreases & Decreases & $\begin{array}{c}\text { Olfactory tubercle hypothalamus } \\
\text { mesolimbic pathway }\end{array}$ & Vascular kidney & 400 \\
\hline & D4 & Decreases & Decreases & frontal cortex midbrain & Heart, kidney & 387 \\
\hline
\end{tabular}

PIP-phosphoinositol phosphate 
protein to induce intracellular signalling (Neve et al. 2004). $\mathrm{D}_{1}$ class receptors $\left(\mathrm{D}_{1}, \mathrm{D}_{5}\right)$, upon DA binding, activate $\mathrm{G \alpha}_{\text {solf }}$ signalling by triggering adenylyl cyclase (AC) and cyclic AMP (cAMP) production. cAMP activates protein kinase $\mathrm{A}$ (PKA), which in turn activates DA and cyclic AMP-regulated phosphoprotein (DARPP-32) by phosphorylating at threonine 34. DARPP-32 is a major signal transduction molecule and a multifunctional protein, which shows different regulatory effects on a variety of signalling molecules when phosphorylated at different active sites. DARPP-32, when phosphorylated at Thr34, acts as an inhibitor for protein phosphatase 1 (PP1), which helps in the amplification of PKA-mediated signalling. When cdk5 phosphorylates DARPP-32 at Thr75 it acts as an inhibitor of PKA. This shows that DARPP-32 can act as a molecular switch for cAMP-mediated signalling (Bibb et al. 1999).

In contrast, $\mathrm{D}_{2}$ class receptors, upon $\mathrm{DA}$ binding, activate $\mathrm{G} \alpha_{\mathrm{i} /}$ signalling, which inhibits cAMP production. Inhibition of cAMP production hampers the PKA-mediated signalling (Damier et al. 1999; Joyce et al. 1997; Rinne et al. 1986; Seeman and Niznik 1990). $\mathrm{D}_{2}$ receptor signalling was observed to regulate $\mathrm{K}^{+}, \mathrm{Na}^{+}$, or $\mathrm{P} / \mathrm{Q}$ type $\mathrm{Ca}^{2+}$ channels involving $\mathrm{G}_{\beta \gamma}$ signalling (Lledo et al. 1992; Okada et al. 2003). DA receptor-mediated signalling is illustrated in Figure 3.

\section{Pathophysiology in neuropsychiatric disorders}

DA at the level of central nervous system (CNS) plays a vital role in cognitive, memory, and various motor functions, any defects in DA signalling cause either over-activation or dysfunction of DA receptors, leading to major psychiatric and neurological disorders such as Parkinson's (PD), schizophrenia, attention deficit with hyperactivity disorder (ADHD), and bipolar disorder (BD) (Moreira et al. 2010). A decrease in dopaminergic signalling or loss of DA neurons in the substantia nigra results in Parkinson's-like symptoms, whereas hyperactive dopaminergic signalling is believed to be a major factor in developing schizophrenia.

Drugs that act as antagonists/agonists on $\mathrm{D}_{2}$ receptors have been used clinically to treat many neuropsychiatric and neurodegenerative disorders. Most of the antipsychotic drugs used in treating disorders like schizophrenia and $\mathrm{BD}$ are based on DA and serotonin receptor antagonism. Clozapine, risperidone, paliperidone, olanzapine, and ziprasidone are atypical antipsychotic

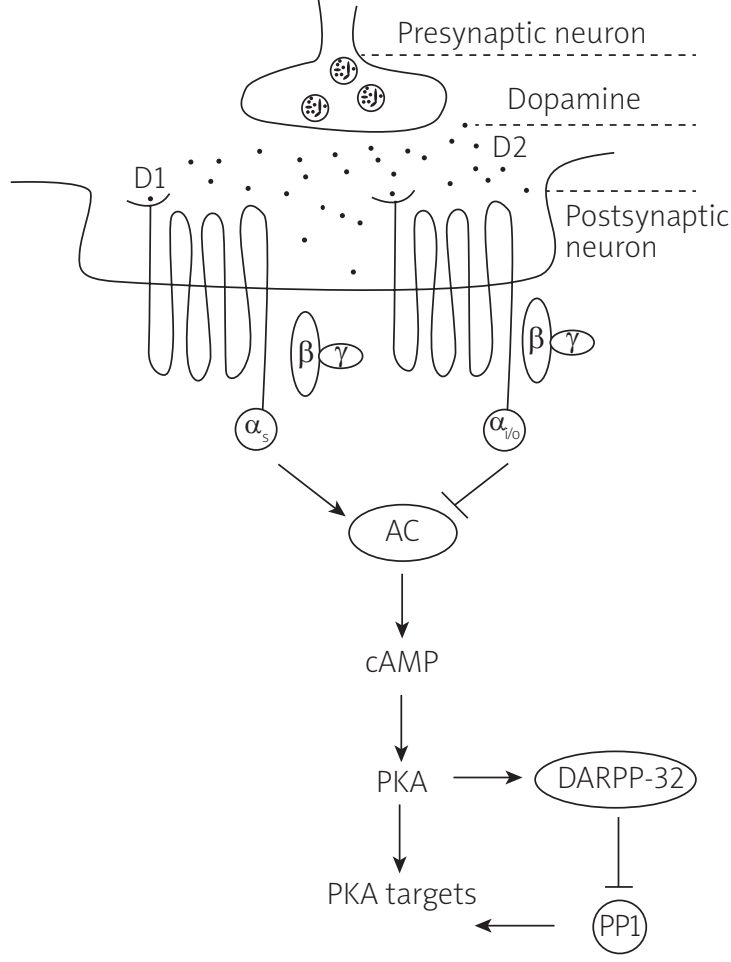

Fig. 3. Schematic representation of dopamine signalling pathway in activating and inhibiting dopamine receptors

drugs, which are based on dopaminergic and serotonin receptor antagonism. Drugs based on DA receptor agonism are capable of activating DA receptors. Apomorphine, bromocriptine, and cabergoline are typical DA receptor agonists, which are currently used as drugs in several neurological disorders. These drugs activate $\mathrm{D}_{2}$ receptors and upregulate several genes involved in dopaminergic signalling through G-proteins and $\beta$-arrestins. DA agonists are used to treat neurological disorders with hypodopaminergic conditions. They are typically used for treating PD and ADHD.

The study of DA-mediated signalling helps in the understanding the molecular events at DA receptors and the molecular mechanism of the disease. It also helps in designing new classes of drugs and developing novel treatment methods. Even though scientists are trying to address various aspects of mental illness and targeting with different classes of drugs, still there exists a gap in untangling the physiology and the specific treatment procedures. In this review, we try to address dopaminergic dysfunction in neuropsychiatric diseases with respect to their pathophysiology, current therapeutics, the unmet medical deficiency, and future perspectives.

Attention deficit hyperactivity disorder 
ADHD is one of the most common psychiatric disorders in children and adults. It is characterised by age-inappropriate persistent symptoms of hyperactivity, inattention, and impulsivity. ADHD in children is marked by a lack of concentration, short attention span, and physical restlessness. People with ADHD have trouble with their orientation in time and space. ADHD is a complex heritable neuropsychiatric disorder in which genetics and environmental factors play a crucial role (Seidler 2001). ADHD is mainly due to inadequate dopaminergic activity in brain reward centres. Dopaminergic dysfunction explains anticipation and preparation problems in children with ADHD, who show reduced activation in the midbrain region. Inadequate DA in the brain drives ADHD-affected children to engage in activities that increase the brain DA level. Among all 42 gene variants involved in ADHD the DAT1 gene was considered an important candidate. DAT1 expresses a DA transporter responsible for moving DA across the presynaptic membrane back into the nerve cell. Drugs used for the treatment of ADHD (methylphenidate [MPH], amphetamine) are based on DA/catecholamine re-uptake inhibition or by mimicking the catecholamine structure. These drugs block DA transporters and norepinephrine transporters in the brain leading to increased concentration of DA and norepinephrine (Robertson et al. 2009). $\mathrm{D}_{1}$ receptor is highly expressed in the PFC and striatum, and has emerged as a therapeutic target for the treatment of ADHD.

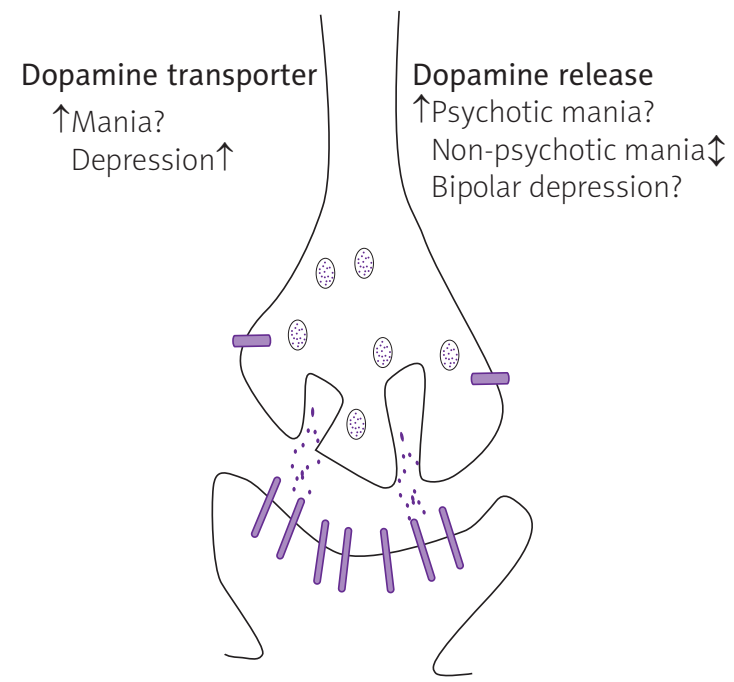

Dopamine transporter $\rightarrow$ Mania? $\rightarrow$ Depression Dopamine release $\rightarrow$ Psychotic mania? $\rightarrow$ Non-psychotic mania $\rightarrow$ Bipolar depression?

Fig. 4. Pathophysiological role of dopamine in the establishment of bipolar disorders
Several neuropsychological studies show that the dysfunction of PFC could account for ADHD, and individuals with impaired PFC exhibit ADHD-like behaviour (Arnsten et al. 1996). Studies have identified several genes susceptible to mediate $\mathrm{ADHD}, \mathrm{DRD}_{2}$ dopamine receptor gene that prevents the expression of normal dopamine receptors in brain reward sites. Genetic variants of dopaminergic genes and other reward genes are important determinants of reward deficiency syndrome (RDS). RDS refers to the breakdown of the cascade of neurotransmitters in the brain, which disrupts the intracellular signalling. Recent studies indicate that RDS in children is mainly due to excessive internet video gaming, which is significantly associated with DA receptor $\mathrm{D}_{2}\left(\mathrm{DRD}_{2}\right)$ A1 allele (Han et al. 2007). Currently, methyphenidate (MPH), a DA/norepinephrine reuptake inhibitor, has been recommended as an effective medication for children with ADHD, but the underlying pharmacological action of the drug is still open to discussion. In addition, MPH, in long-term usage, resulted in cardiovascular impairment such as irregular heartbeat and characteristic increase in blood pressure, giving the notion that treatment for ADHD still remained unravelled with respect to its mechanism of action and limiting side effects (Ruocco et al. 2009). Hence, we can say that this remains an area open for research.

\section{Bipolar disorder}

$\mathrm{BD}$ is a common neuropsychiatric disorder and severe mental illness with unusual shifts in mood, energy, activity levels, and the ability to carry out day-to-day tasks. About $2-4 \%$ of the general population worldwide is suffering with $\mathrm{BD}$, and it is one of the leading neuropsychiatric disorders (Merikangas et al. 2011). BD is characterised by having two major phases of illness: recurrent episodes of mania, which exists for several weeks, followed by a depression phase for several weeks. BD is also characterised by an inter episode of mood instability and mixed state of both maniac and depressive phases (Judd et al. 2005). The DA hypothesis was proposed in the early 1970s and has been a key theory in understanding the symptoms of manic and depressive phases of the illness (Tissot 1975; Wittenborn 1974). According to DA theory, hyperdopaminergia might be the underlining cause for the manic phase, and hypodopaminergia for the depressive phase. However, this theory does not explain how hyper- and hypodopaminergic conditions arise in $\mathrm{BD}$. Later, another 
theory hypothesised that a faulty homoeostatic mechanism is responsible for the existence of hyper- and hypodopaminergic conditions in $\mathrm{BD}$ (Cousins et al. 2009).

A brief explanation is shown in Figure 4, of how DA might play a role in disease establishment. Several studies suggest $\mathrm{D}_{2}$ receptor upregulation in the dorsolateral PFC in BD (Kaalund et al. 2014). BD patients with psychotic mania showed elevated $\mathrm{D}_{2} / \mathrm{D}_{3}$ receptor density when compared with healthy controls and non-psychotic mania patients (Wong et al. 1997). Several fMRI studies support the existence of abnormal reward-related neuronal activity in the ventral striatum and frontal cortex, suggesting the dopaminergic dysfunction in $\mathrm{BD}$ (Nusslock et al. 2014). Because BD includes two categories of diseased condition and DA has been proven to be a key player in the onset of the disease condition, DA receptors have been targeted for the treatment of patients. Hence, depending upon the patient's condition, treatment is given using either DA receptor antagonists or agonists or the DOPA precursor, which blocks tyrosine production. DA antagonists and partial agonists like olanzapine, risperidone, quetiapine, and aripiprazole were approved by the U.S. Food and Drug Administration (FDA) and are used in the treatment of acute manic phase as well as depressive phases of BD (Ketter et al. 2014). Current therapy available for $\mathrm{BD}$, targeting $\mathrm{DA}$ and its receptors, is shown in Table 2 (Ashok et al. 2017).

\section{Schizophrenia}

Schizophrenia is a major psychotic disorder characterised by delusions, disorganised behaviour, hallucinations, and cognitive difficulties. Even though the clinical manifestation of schizophrenia varies from one individual to another, there ex- ists a core of common symptoms of the disease. These symptoms include abnormal thoughts and perceptions, motor abnormalities, and cognitive defects. The symptoms of schizophrenia are usually termed either positive or negative. Positive symptoms include hallucinations, delusions, inappropriate affect (emotions), and thought disorder. Negative symptoms include social withdrawal, poverty of thought and speech, impaired volition, and blunted affect (Birtwistle and Baldwin 1998). Cognitive defects in schizophrenia affect attention inhibition, working memory, language and executive function, and sensory processing. Out of the many theories to explain the pathophysiology of schizophrenia the most enduring has been the DA hypothesis (Barch and Ceaser 2012). The DA hypothesis was proposed by Van Rossum in 1967 (van Rossum 1966). Several studies found elevated levels of $\mathrm{D}_{1} \mathrm{mRNA}$ in the parieto-temporal cortex and $\mathrm{D}_{2} \mathrm{mRNA}$ in the frontal cortex in schizophrenia patients (Barch and Ceaser 2012; Tallerico et al. 2001). Recent studies indicate a significant increase in the levels of tyrosine hydroxylase rate limiting enzyme involved in DA synthesis, suggesting increased production of DA in the midbrain (Boyd and Mailman 2012). Studies using positron emission tomography imaging (PET) showed abnormally high subcortical synaptic DA release after using DA stimulants like amphetamine, which induced psychotic symptoms in healthy individuals (Angrist and Van Kammen 1984). This evidence indicates that there is a presynaptic hyperdopaminergic abnormality in schizophrenia, and the antipsychotic drugs used to treat the disorder act by blocking DA receptors. However, recent studies indicate that glutamate, g-aminobutyric acid (GABA), acetylcholine (ACTH), and serotonin alterations are also involved in the pathophysiology of schizophrenia.

Table 2. Summary of pharmacological evidence on dopamine dysfunction in bipolar disorder

\begin{tabular}{|c|c|c|c|}
\hline $\begin{array}{l}\text { Phase } \\
\text { of illness }\end{array}$ & Drug & Mechanism of action & Effect \\
\hline \multirow[t]{3}{*}{ Mania } & Levodopa & Dopamine precursor & $\begin{array}{c}\text { Induced mania and hypomania in Parkinsonian } \\
\text { patients }\end{array}$ \\
\hline & Bromocriptine & Dopamine agonist & $\begin{array}{l}\text { Induced mania in some patients who received } \\
\text { it for postpartum galactorrhoea }\end{array}$ \\
\hline & Amphetamine & $\begin{array}{l}\text { Increases dopamine } \\
\text { release }\end{array}$ & $\begin{array}{l}\text { Induced mania-like symptoms in healthy } \\
\text { volunteers }\end{array}$ \\
\hline \multirow[t]{3}{*}{ Depression } & Pramipexole & D2/D3 agonist & Short-term efficacy in bipolar depression \\
\hline & $\begin{array}{l}\text { Methylphenidate } \\
\text { and amphetamine }\end{array}$ & $\begin{array}{l}\text { Increases dopamine } \\
\text { release }\end{array}$ & $\begin{array}{c}\text { Beneficial in bipolar depression patients with } \\
\text { drowsiness and fatigue }\end{array}$ \\
\hline & $\begin{array}{c}\text { Olanzapine-fluoxetine } \\
\text { combination, quetiapine, } \\
\text { and lurasidone }\end{array}$ & $\begin{array}{l}\text { D2 blockade and } \\
\text { serotonergic effects }\end{array}$ & Efficacy in bipolar depression \\
\hline
\end{tabular}


Most of the anti-psychotic drugs developed for schizophrenia were based on DA antagonism. Two major factors associated with schizophrenia are DA receptor $\left(\mathrm{D}_{2}\right)$ hyperactivity in the frontal cortex and increased DA release. Due to the tight correlation between the clinical potency and the D-blocking action of the antipsychotic drugs, DA hyperactivity could be the underlying cause of schizophrenia (Greif et al. 1995; Kebabian and Greengard 1971; Lledo et al. 1992; Romanelli et al. 2010). Schizophrenia patients with increased $\mathrm{D}_{2}$-receptor occupancy (above $80 \%$ ) were observed to have extrapyramidal syndromes (EPSs). Clozapine is an effective anti-psychotic drug, but it was observed to have EPS side effects. New-generation atypical anti-psychotic drugs, like risperidone, have been synthesised to replicate the effectiveness of clozapine, but without its side effects, by having a high 5-hydroxytryptamine (5-HT) $2 \mathrm{~A} / \mathrm{D}_{2}$ occupancy ratio. Lower doses of antipsychotics such as risperidone are effective and do not induce extrapyramidal syndrome (Enjalbert and Bockaert 1983; Lee et al. 1978). All the existing medication for treating schizophrenia either interact directly with DA receptors or non-DA receptors such as $\mathrm{N}$-methyl-d-aspartate(NMDA)-, 2-amino-3-(3hydroxy-5-methyl-4-isoxazolyl (AMPA)-propionic acid, GABA, and nicotinic-receptors. Targeting DA receptors and synthesising/purifying novel therapeutic molecules requires cutting-edge technology to identify new chemical entities (NCEs) and to improve the patient's condition by minimising side effects.

\section{Parkinson's disease}

$\mathrm{PD}$ is a long-term degenerative and progressive extrapyramidal motor disorder. Statistically, PD is considered as the second most commonly occurring neurodegenerative disorder in the

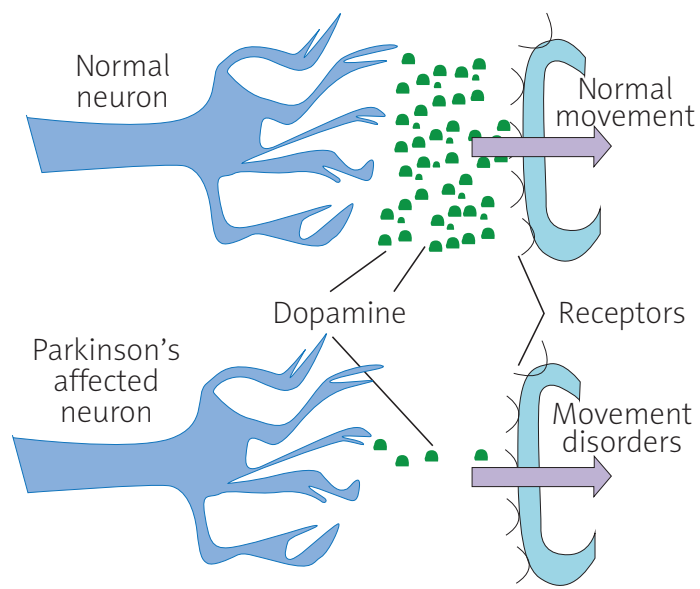

Fig. 5. Schematic representation of development of Parkinso n's disease at molecular level world. The cause of PD is unknown, but genetic and environmental factors play a crucial role. Some factors that are grouped under non-genetic risk factors, such as alcohol, coffee, and tobacco consumption, and a few types of dietary fats, also partly impart the onset of PD. Increased cytokine production is observed in the spinocerebral fluid of PD patients, giving a notion that inflammation could also be a possible risk factor for the emergence of PD (De Lau and Breteler 2006). From the current survey, it is known that the onset of disease is seen mostly in old people aged around 50-60 years, and the risk is approximately ten-fold higher in men aged 70-80 years. Men are more commonly diagnosed with PD than women because of the existence of oestrogens. Loss of DA is the marker for diagnosing patients suffering from PD, even though $90 \%$ of DA degradation can be seen in the substantial nigra region, even before the patient develops clinical symptoms. Under physiological conditions, it is known that DA and ACTH act complementarily, due to which patients with PD are often characterised by selective dopaminergic neuronal degeneration in the substantia nigra, which leads to shaking, rigidity, slowness of movement, difficulty walking, and dementia (Fig. 5). Current literature reports that metabolic stress could be the most important reason for the degeneration of DA neurons. A few selective voltage-gated ion channels, specifically $\mathrm{Ca}^{2+}$ channels and ATP pumps under metabolic stress, fail to maintain membrane potential, thereby causing an imbalance in ion concentrations. These fluctuations in turn affect the neuronal network and cause DA neuron degeneration. Because the symptoms cannot be identified at an earlier state of onset of disease, providing treatment on time is difficult for PD patients. To find early symptoms and protect DA neurons from degradation is the biggest challenge to date. Some studies show that supplementing PD patients with vitamin $\mathrm{E}$ or $\mathrm{C}$ at optimal doses is a potential treatment, because vitamin $\mathrm{C}$ produces large amounts of anti-oxidants, which can relieve a cell from metabolic stress by inhibiting the production of free radicals and reactive oxygen (Dragicevic et al. 2015). DA receptor agonists are generally used to treat PD, which act by stimulating both presynaptic and postsynaptic dopaminergic receptors. DA deficiency in PD is substituted by a chemical precursor L-DOPA, which is the most effective drug to treat various symptoms (Seeman and Niznik 1990; Damier et al. 1999). Extensive research should be done 
in order to find the risk factors involved in the early stages of PD; diagnosing the symptoms during disease progression and finding a better protection of neuronal degeneration are still a matter of debate. The emergence of advanced technology and tools being developed over time will definitely aid in finding the questionnaire.

\section{Alzheimer's disease}

Alzheimer's disease (AD) is a major neurodegenerative disorder characterised by progressive decline in cognitive skills leading to dementia. It is more likely to affect elderly people aged over 60 years, and a recent survey shows that this is the world's third most common cause of death in this group other than heart disease and cancer. Dementia is the most commonly seen symptom with patients of $A D$. The reasons for the onset and progression of $\mathrm{AD}$ include health, lifestyle, and some environmental risk factors. Health conditions such as heart diseases and metabolic disorders like diabetes and obesity affect the brain function because there is an existing link between cognitive impairment and the cardiovascular system. Environmental social lifestyle habits including physical inactivity, unhealthy food habits, and changed way of living affect brain stimulation with respect to cognitive pathways, and hence before manifestation of disease symptoms internal damage takes place, and treatment does not make any difference with the patients, altogether giving us a notion that still more research is required to explore the disease manifestation, in order to find the specific external symptoms and diagnostic methods. It is believed, and proven to an extent, that DA has an evident role in the development of the disease. A decrease in dopaminergic signalling is one of the major causes of cognitive decline in $\mathrm{AD}$. Several studies reported a decline in $\mathrm{D}_{2}$ receptor expression in the hippocampus and frontal cortex. A decrease in DA release for nerve terminal results in reduced expression of DAT and tyrosine hydroxylase enzymes leaving high amount of tyrosine (Bressan et al. 2003; Farde 1997; Seeman 2011, 2010b). AD pathophysiological symptoms like apathy, negative prognostic is suggested to be the consequence of impairment of DA transmission (Robert et al. 2010). Parkinson's symptoms in AD might be due to a change in the number of postsynaptic DA receptors. Using DA agonists as drugs showed beneficial effects on some cognitive symptoms in AD patients (Koch et al. 2013). A significant physiological change in brain tissue is seen in patients with $\mathrm{AD}$ is the formation of unusual tangled protein clumps, which are now being referred to as amyloid plaques and tau proteins. This kind of protein clump formation leads to the shrinkage or degradation of brain tissue and finally leads to the loss of neuronal connections, thereby impairing the cognitive system.

A wide range of FDA-approved medications, like, donepezil, rivastigmine, and galantamine, which are acetylcholine esterase inhibitors, are currently used to treat mild to moderate AD. Donepezil can be used for severe AD as well (Alzheimers, A. [2005]. Alzheimers Disease Fact Sheet). Even though a lot of research has been done in this regard, there is still the unanswered question of how to diagnose and treat $\mathrm{AD}$ at a very early stage. Scientists are still investigating to find out the specific drug target and new classes of drugs and this matter remains an open debate.

\section{Future perspectives}

Neuro psychiatric disorders are the most complex brain disorders, which are difficult to treat. Some newer-generation atypical anti-psychotic drugs were able to minimise the side effects; however, they are unable to control the negative symptoms and cognitive defects caused by these disorders. With the limited knowledge of signalling pathways and genes involved, it is difficult to develop newer classes of drugs by traditional methods, increase the efficacy, and minimise the side effects. Thus, there is a clear need in using newer strategies in designing and developing novel antipsychotic drugs. With the advent of computer-based technology, it is possible to find a solution and bring better treatment procedures for complex disorders. One such advancement is computer-aided drug design (CADD). CADD has emerged as an effective tool to minimise time and cost of the new lead molecules. It requires basic knowledge about the disease pathophysiology and important proteins involved in the progression of disease. CADD, on a broad perspective, is classified into two categories (Fig. 6): structure-based (SB) and ligand-based (LB). Structure-based drug discovery includes finding a target first. If the crystal structure of the protein of interest does not exist, it has to be modelled using homology modelling tools. Once the crystal structure is ready, it can be used to screen several small molecules from the existing small molecule databases. On the other hand, one can synthesise NCEs using de novo approaches. Ligand-based CADD includes pharmacophore mapping, structure activity relationships (SAR) like 3D-QSAR. Upon 


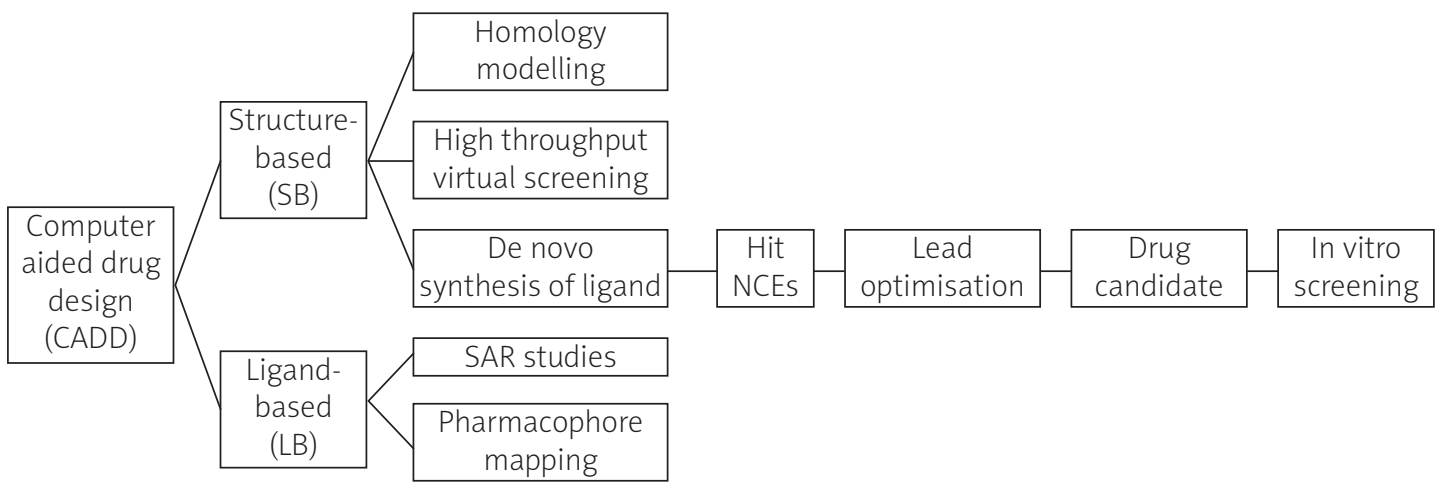

Fig. 6. Overview of computer-aided drug design

docking the target with several small molecules, a few hit molecules will be identified and are further optimised by running molecular dynamics and simulations through which lead molecules can be identified. These lead molecules are screened against the targets in vitro and will be assessed for their activity, i.e. in preclinical trials. Molecules that show the expected outcome will be treated as drug candidates and can be used for the clinical trials. Altogether this is a costeffective method of finding new drug molecules. Even though very few dopaminergic signalling proteins have been reported with their crystal structures to date, more refined crystals are expected to come. Usage of high-throughput technology integrating with existing knowledge of neurological signalling certainly gives hope for future therapeutics in neuropsychiatry.

\section{Conclusions}

Antipsychotic drugs, also known as neuroleptics, were discovered in the 1950s. Subsequently several generations were developed to treat positive symptoms of neuropsychiatric disorders. However, the underlying cause for the occurrence of psychiatric disorders is still unclear, and most of the antipsychotic drugs were developed as DA receptor blockers. Dopaminergic signalling is crucial for a variety of brain functions, and abnormal DA regulation leads to several neuropsychiatric disorders, although antipsychotic drugs were developed 60 years ago, and the efficacy of these drugs has not much improved. Newer generation atypical antipsychotic drugs are able to minimise the side effects caused by older generation drugs; however, the negative symptoms and cognitive defects are much less responsive to current generation drugs. Thus, there is a clear need to develop novel therapeutic strategies in designing/discovering newer classes of drugs. This is possible only by having clear knowledge about DA regulation and dopaminergic signalling. An in silico approach can be a tool for extensively studying the DA receptors and other protein targets involved in dopaminergic signalling, and this gives a clear-cut idea of targets, which aids in designing NCEs. Molecular docking and pharmacokinetic studies can further help in screening NCEs, and the lead molecules can be studied by setting up a few in vitro cell-based assays, in which the activities of the lead molecules can be assessed. This study can be upgraded by pursuing in vivo studies for validating the efficacy of targets and NCEs as well. All this can be made possible by integrating the available cutting-edge technology with our knowledge on DA signalling, which gives future generations a promising treatment for neurological disorders.

\section{Acknowledgements}

The authors are grateful to the Science Education Research Board (SERB), Department of Science and Technology (DST), Govt. of India for the grant (ECR/2016/001673) and for supporting Ms. Sobhitha with her Junior Research Fellowship. We would like to thank the management of the Koneru Lakshmiah Education Foundation for helping us with necessary resources.

\section{References}

1. Andén NE, Carlsson A, Dahlström A, Fuxe K, Hillarp NÅ, Larsson K. Demonstration and mapping out of nigro-neostriatal dopamine neurons. Life Sci 1964; 3: 523-530.

2. Angrist B, Van Kammen DP. CNS stimulants as tools in the study of schizophrenia. Trends Neurosci 1984; 7: 388-390.

3. Arnsten AF, Steere JC, Hunt RD. The contribution of alpha 2-noradrenergic mechanisms of prefrontal cortical cognitive function. Potential significance for attention-deficit hyperactivity disorder. Arch Gen Psychiatry 1996; 53: 448-455.

4. Ashok AH, Marques TR, Jauhar S, et al. The dopamine hypothesis of bipolar affective disorder: the state of the art and implications for treatment. Mol Psychiatry 2017; 22: 666.

5. Barch DM, Ceaser A. Cognition in schizophrenia: core psychological and neural mechanisms. Trends Cogn Sci 2012; 16: 27-34.

6. Bibb JA, Snyder GL, Nishi A, et al. Phosphorylation of DARPP-32 by Cdk5 modulates dopamine signalling in neurons. Nature 1999; 402: 669-671.

7. Birtwistle J, Baldwin D. Role of dopamine in schizophrenia and Parkinson's disease. Br J Nurs 1998; 7: 832-841. 
8. Boyd KN, Mailman RB. Dopamine receptor signaling and current and future antipsychotic drugs. Handb Exp Pharmacol 2012; 212: 53-86.

9. Bressan RA, Erlandsson K, Jones HM, et al. Optimizing limbic selective D2/D3 receptor occupancy by risperidone: A [123I]-epidepride SPET study. J Clin Psychopharmacol 2003; 23: 5-14

10. Cousins DA, Butts K, Young AH. The role of dopamine in bipolar disorder. Bipolar Disord 2009; 11: 787-806.

11. Dahlström A, Fuxe K. Evidence for the existence of monoamine-containing neurons in the central nervous system. I. Demonstration of monoamines in the cell bodies of brain stem neurons. Acta Physiol Scand Suppl 1964; 1-55.

12. Damier P, Hirsch EC, Agid Y, Graybiel AM. The substantia nigra of the human brain: II. Patterns of loss of dopamine-containing neurons in Parkinson's disease. Brain 1999; 122: 1437-1448.

13. De Lau LML, Breteler MMB. Epidemiology of Parkinson's disease. Lancet Neurol 2006; 5: 525-535.

14. Dragicevic, E, Schiemann J, Liss, B. Dopamine midbrain neurons in health and Parkinson's disease: emerging ro les of voltage-gated calcium channels and ATP-sensitive potassium channels. Neuroscience 2015; 284: 798-814.

15. Enjalbert A, Bockaert J. Pharmacological characterization of the D2 dopamine receptor negatively coupled with adenylate cyclase in rat anterior pituitary. Mol Pharmacol 1983; 23: 576-584.

16. Farde L. Brain imaging of schizophrenia - the dopamine hypothesis. Schizophr Res 1997; 28: 157-162.

17. Greif GJ, Lin YJ, Liu JC, Freedman JE. Dopamine-modulated potassium channels on rat striatal neurons - specific activation and cellular expression. J Neurosci 1995; 15: 4533-4544.

18. Han DH, Lee YS, Yang KC, et al. Renshaw, P.F. Dopamine genes and reward dependence in adolescents with excessive internet video game play. J Addict Med 2007; 1: 133-138.

19. Joyce JN, Smutzer G, Whitty CJ, et al. Differential modification of dopamine transporter and tyrosine hydroxylase mRNAs in midbrain of subjects with Parkinson's, Alzheimer's with parkinsonism, and Alzheimer's disease. Mov Disord 1997; 12: 885-897.

20. Judd LL, Akiskal HS, Schettler PJ, et al. Psychosocial Disability in the Course of Bipolar I and II Disorders. Arch Gen Psychiatry 2005; 62: 1322

21. Kaalund SS, Newburn EN, Ye T, et al. Contrasting changes in DRD1 and DRD2 splice variant expression in schizophrenia and affective disorders, and associations with SNPs in postmortem brain. Mol Psychiatry 2014; 19: 1258-1266.

22. Kebabian JW, Greengard P. Dopamine-Sensitive Adeny Cyclase: Possible Role in Synaptic Transmission. Science 1971; 174: 1346-1349.

23. Ketter TA, Miller S, Dell'Osso B, et al. Balancing benefits and harms of treatments for acute bipolar depression. Affect Disord 2014; 169: S24-S33.

24. Koch G, Belli L, Giudice TL, et al. Frailty among Alzheimer's disease patients. CNS Neurol Disord Drug Targets 2013; 12: 507-511.

25. Lee T, Seeman P, Rajput A, et al. Receptor basis for dopaminergic supersensitivity in Parkinson's disease. Nature 1978; 273: 59-61.

26. Lledo PM, Homburger V, Bockaert J, Vincent JD. Differential $G$ protein-mediated coupling of D2 dopamine receptors to $\mathrm{K}+$ and $\mathrm{Ca} 2+$ currents in rat anterior pituitary cells. Neuron 1992; 8: 455-463.

27. Merikangas KR, Jin R, He J-P, et al. Prevalence and correlates of bipolar spectrum disorder in the world mental health survey initiative. Arch Gen Psychiatry 2011; 68: 241-251.

28. Moreira IS, Shi L, Freyberg Z, et al. Structural basis of dopamine receptor activation. In: The Dopamine Receptors, Neve KA (ed.). Humana Press, Totowa, NJ 2010; 47-73.

29. Musacchio JM. Enzymes Involved in the Biosynthesis and Degradation of Catecholamines. In: Biochemistry of Biogenic Amines, Iversen L (ed.). Springer US, New York 1975; 1-35.

30. Neve KA, Seamans JK, Trantham-Davidson H. Dopamine receptor signaling. J Recept Signal Transduct Res 2004; 24: 165-205.
31. Niznik HB, Van Tol HH. Dopamine receptor genes: new tools for molecular psychiatry. J Psychiatry Neurosci 1992; 17: 158-180.

32. Nusslock R, Young CB, Damme KSF. Elevated reward-related neural activation as a unique biological marker of bipolar disorder: assessment and treatment implications. Behav Res Ther 2014; 62: 74-87.

33. Okada Y, Miyamoto T, Toda K. Dopamine modulates a voltage-gated calcium channel in rat olfactory receptor neurons. Brain Res 2003; 968: 248-255.

34. Rankin ML, Marinec PS, Cabrera DM, et al. The D1 dopamine receptor is constitutively phosphorylated by G protein-coupled receptor kinase 4. Mol Pharmacol 2006; 69: 759-769.

35. Rinne JO, Sako E, Paljarvi L, et al. Brain dopamine D-2 receptors in senile dementia. J Neural Transm 1986; 65: 51-62.

36. Robert PH, Mulin E, Malléa P, David R. Review: Apathy Diagnosis, Assessment, and Treatment in Alzheimer's Disease. CNS Neurosci Ther 2010; 16: 263-271.

37. Robertson SD, Matthies HJG, Galli A. A closer look at amphetamine-induced reverse transport and trafficking of the dopamine and norepinephrine transporters. Mol Neurobiol 2009; 39: 73-80.

38. Romanelli RJ, Williams JT, Neve KA. Dopamine Receptor Signaling: Intracellular Pathways to Behavior. In: The Dopamine Receptors, Neve KA (ed.). Humana Press, Totowa, NJ 2010; 137-173.

39. Rondou P, Haegeman G, Van Craenenbroeck K. The dopamine D4 receptor: biochemical and signalling properties. Cell Mol Life Sci 2010; 67: 1971-1986.

40. Ruocco LA, de Souza Silva MA, Topic B, et al. Intranasal application of dopamine reduces activity and improves attention in Naples High Excitability rats that feature the mesocortical variant of ADHD. Eur Neuropsychopharmacol 2009; 19: 693-701.

41. Seeman P. All Roads to Schizophrenia Lead to Dopamine Supersensitivity and Elevated Dopamine D2High Receptors. CNS Neurosci Ther 2011; 17: 118-132.

42. Seeman P. Historical Overview: Introduction to the Dopamine Receptors. In: The Dopamine Receptors, Neve KA (ed.). Humana Press, Totowa, NJ, 2010a; 1-21.

43. Seeman P. Dopamine D2 receptors as treatment targets in schizophrenia. Clin Schizophr Relat Psychoses 2010b; 4: 56-73.

44. Seeman P, Niznik HB. Dopamine receptors and transporters in Parkinson's disease and schizophrenia. FASEB J 1990; 4: 2737-2744.

45. Seidler R. Amphetamine. Curr Ther 2001; 42: 86-87.

46. Tallerico T, Novak G, Liu ISC, et al. Schizophrenia: elevated mRNA for dopamine D2Longer receptors in frontal cortex. Mol Brain Res 2001; 87: 160-165.

47. Tiberi M, Jarvie KR, Silvia C, et al. Cloning, molecular characterization, and chromosomal assignment of a gene encoding a second D1 dopamine receptor subtype: differential expression pattern in rat brain compared with the D1A receptor. Proc Natl Acad Sci U S A 1991; 88: 7491-7495.

48. Tissot R. The common pathophysiology of monoaminergic psychoses: a new hypothesis. Neuropsychobiology 1975; 1: 243-260.

49. van Rossum JM. The significance of dopamine-receptor blockade for the mechanism of action of neuroleptic drugs. Arch Int Pharmacodyn Ther 1966; 160: 492-494.

50. Wittenborn JR. Deductive approaches to the catecholamine hypothesis of affective disorders. J Nerv Ment Dis 1974; 158: 320-324.

51. Wong DF, Pearlson GD, Tune LE. Quantification of neuroreceptors in the living human brain: IV. Effect of aging and elevations of D2-like receptors in schizophrenia and bipolar illness. J Cereb Blood Flow Metab 1997; 17: 331-342. 